\title{
EL CONSENSO EN LA IMPLANTACIÓN DE LOS REGÍMENES DEMOCRÁTICOS: 1931 Y 1978*
}

\author{
Glicerio Sánchez Recio
}

\section{EL CONCEPTO DE CONSENSO}

El término consenso es sin duda uno de los más utilizados en los medios políticos, periodísticos e historiográficos en los últimos veinticinco años pero, a la vez, es un término cuyo significado se mantiene impreciso y los analistas y comentaristas lo sitúan en un terreno poco definido, entre la "mayoría" y la "unanimidad", ya que se alude a él preferentemente en la elaboración de las leyes y en la toma de decisiones políticas. Por lo tanto, considero labor prioritaria en este trabajo precisar el significado de consenso o, al menos, fijar los límites semánticos dentro de los cuales lo colocaré cuando me refiera a él.

El diccionario de la RAE (1980) lo define como "consentimiento [conformidad de voluntades], y más particularmente el de todas las personas que componen una corporación». Acepción que lo situaría respecto al asunto que nos ocupa en la expresa unanimidad; en cambio, el Diccionario del Uso del Español [María Moliner] traduce el consentimiento como «conformidad de una persona con una cosa o acuerdo de varias personas entre sí» y pone como ejemplo ilustrativo: "las fuerzas políticas han logrado el consenso para afrontar los graves problemas económicos». Definición y ejemplo que introducen matices muy significativos y de gran utilidad en este caso:

Primero, que de la conformidad con una cosa o asunto de que se trate no se dice expresamente que haya de ser unánime y que la expresión «las fuerzas políticas que logran el consenso» implica que alguna de ellas pueda quedarse al margen.

\footnotetext{
* Este trabajo se inserta dentro del proyecto de investigación financiado por el Ministerio de Educación y Ciencia, HUM2005-03816, «Del consenso constitucional al enfrentamiento partidista en España, 1977-2004».
} 
Segundo, que el consenso no afecta preferentemente al final de un proceso, es decir, a la toma de decisiones o la fijación de posiciones, sino más bien al principio del mismo. El consenso, según el ejemplo anterior, se ha logrado para afrontar los graves problemas económicos. Por lo tanto, el acuerdo es previo a cualquier tipo de decisiones y su objeto sería el convencimiento y la seguridad intelectual de que existe un grave problema económico y la necesidad compartida por todas las fuerzas políticas, o por la mayoría, de superarlo.

En este sentido, el consenso, como consentimiento mayoritario y no unánime por necesidad, ha de situarse al comienzo del proceso de que se trate e incluir la voluntad manifiesta de llegar al final, pero los elementos que lo configuren pueden ser objeto de consensos sucesivos o de acuerdos mayoritarios.

Un ejemplo claro de este tipo de consenso se plantea ya en los comienzos de la transición a la democracia en España. En un artículo de Julián Marías, publicado en El País, el 24 de agosto de 1976, cuando aún no se había elaborado el proyecto de "ley para la reforma política", se enunciaban los objetivos políticos inmediatos de la siguiente manera:

«La política... debería intentar, más bien, reducir los puntos de fricción, aplazar para más adelante las cuestiones secundarias y los matices, renunciar a los motivos de discordia, enfrentarse con la empresa difícil de salvar la modesta prosperidad del pueblo español -ya tan comprometida-, devolverle su plena libertad,... asegurar el estricto respeto a la vida, a la expresión de las opiniones, a las diferencias, a la proyección histórica de España»${ }^{1}$.

En este texto, evidentemente, están enunciados los objetivos políticos prioritarios de la mayor parte de la sociedad española a los pocos meses de la muerte del dictador, que configurarían el consenso, y la condición que debería consolidarse con el proceso de transición, mantener el status económico y social de la población.

Otro ejemplo en la misma dirección puede hallarse en el artículo editorial de Diario 16, del 16 de noviembre de 1976. Cuando las Cortes franquistas no habían aprobado todavía la "ley para la reforma política», el editorialista estaba tratando ya del carácter de la próxima Constitución y situando el consenso en el transcurso de su diseño:

«La futura constitución no puede ser un texto impuesto por el partido o la coalición de partidos vencedores. Tampoco puede ser la encarnación exclusiva de una ideología dominante... La constitución debe concebirse, por el contrario, como un acuerdo mínimo de todos los grupos, de todas las tendencias, esto es, como la expresión de un consenso. Nadie debe intentar convertir en texto constitucional su propio programa político»².

1. El artículo se titulaba «Ganar tiempo y perder el tiempo» y el texto reproducido se hallaba bajo un epígrafe titulado "Consenso minado».

2. Los dos periódicos citados son los representantes más genuinos de la prensa independiente, reformista y democratizadora, sin adherencias del pasado, abiertos a los análisis más objetivos y a los debates con mayor proyección de futuro. Este mismo planteamiento era el expuesto por Miguel HeRRERO DE MiÑón (miembro de la ponencia constitucional del Congreso de los Dipu- 
De forma complementaria se expresaba el sociólogo y político Raúl Morodo, en septiembre de 1978, analizando el consenso desde el punto de vista metodológico "como procedimiento para obtener acuerdos». En este sentido la teoría sociológica del consenso se relacionaría con la teoría del conflicto, y el consenso sería «una respuesta estratégica política a una situación social determinada que suscita múltiples cuestiones», entre ellas el cambio de relaciones entre el Gobierno y la oposición. De esta forma, el consenso funcionaría como «una violencia simbólica, que ocultaría los conflictos de racionalidades en la sociedad global, asegurando así, a la vez, cohesión mínima y la legitimación de pretensiones». En este caso, el consenso no puede institucionalizarse permanentemente y transformarse en orgánico. El consenso, por lo tanto, como soporte procedimental, tiene un carácter de coyuntura, dependiendo de unas determinadas condiciones sociales y políticas entendidas de forma dinámica, lo que lo hace apto para un proceso de asentamiento inicial para establecer reglas de juego aceptadas por la inmensa mayoría ${ }^{3}$.

Pero el término consenso, como otros muchos, particularmente los utilizados en la construcción de las Ciencias Sociales, están sometidos a su propia historia. El «consenso» alcanzó el estrellato en España en los años setenta, en el contexto político de la disolución del régimen franquista y de la transición democrática. Se difundió el uso por la influencia sobre los españoles de los comentaristas, historiadores y politólogos italianos y fue asumido por la mayoría de la opinión pública y los analistas al comprender que expresaba muy bien el estado de opinión mayoritario -o el convencimiento- de lo que era deseable que sucediera a la muerte del general Franco. Sin embargo, en 1931, cuando se diluyó la Monarquía y se implantó por primera vez en España un régimen democrático, ni el consenso fue tan generalizado como el de los años setenta ni en los textos periodísticos ni en los de los políticos aparece el uso de tal término.

En un periódico republicano, Ahora, que puede calificarse como de "centro reformista», en septiembre de 1931, una vez presentado en las Cortes el proyecto constitucional, se hablaba, como desideratum, de "constitución nacional», entendiendo por ella «una bandera de paz bajo la cual podamos cobijarnos todos"; y en lugar de consenso se hablaba de transigencia que, evidentemente, no es lo mismo pero que incluye alguno de los elementos de aquél [ceder en algo para llegar a un acuerdo con alguien]. Y refiriéndose al proyecto constitucional escribía el editorialista, casi en paralelo a lo visto más arriba respecto a la de 1978:

tados) en su artículo "Falsas y verdaderas vías del consenso constitucional», Revista de Estudios Politicos (Nueva Época), n. ${ }^{\circ} 9$ (1979), Madrid, pp. 73-97, en el que concluía: «La constitución no puede ser obra de unos pocos impuesta al resto de la comunidad. No debe ser siquiera la obra de una mayoría que no comprende en su resultado, al menos virtualmente, el asentimiento de la minoría. La constitución, pues, ha de ser de todos. En ello consiste la concordia (...) La constitución de todos es la que vincula a todos por igual, y ello sólo es posible cuando, reafirmando el carácter normativo de la constitución, se encomienda a los juristas la determinación de su sentido objetivo...", p. 97.

3. Morodo, Raúl, «La función político-social del 'consensus'», El País, 23 de septiembre de 1978. 
«Una constitución debe ser una obra de transigencia. Se trata del Estatuto por el que han de regirse todos los españoles, y por esto mismo no puede ser obra exclusiva de partido" ${ }^{4}$.

Para expresar la misma idea, El Debate, periódico confesional de la ACNP, empleaba la expresión "fórmula de convivencia»".

Así pues, los términos que se utilizaban a comienzos de los años treinta y mediados de los setenta para expresar las mismas o semejantes ideas eran distintos como también eran las situaciones de partida y las realidades sociopolíticas de los españoles, que analizaremos más adelante.

\section{EL CONSENSO DE 1931 Y 1978}

Para desarrollar este enunciado es preciso hacer referencia a la situación política y social de los españoles en ambas coyunturas históricas. Puede decirse, en primer lugar, que se daba una cierta similitud entre la situación sociopolítica existente en la primavera de 1931 y la de finales de 1975. En ambos casos se agotaba un régimen de dictadura, durante los cuales se había aplicado una intensa reducción en el reconocimiento y ejercicio de los derechos civiles y políticos. No es ajeno a esta situación que en las constituciones democráticas de 1931 y 1978 los respectivos títulos dedicados a los derechos fundamentales alcanzaran un desarrollo tan amplio.

Pero también puede decirse que las similitudes terminan ahí ya que la dictadura del general Primo de Rivera fue la salida natural de la crisis del régimen de la Restauración, no en balde fue apoyado por la Corona, y que, a pesar de su declarada intención de promover su reforma [democratización], quedó varado en formas de gobierno autoritario apoyándose en los elementos y grupos más conservadores de la sociedad. La caída de la dictadura supuso el cierre a la continuidad de la Monarquía que quedó incapacitada para restablecer la Constitución de 1876, que ella misma había invalidado en septiembre de 1923.

La actitud de la Monarquía durante la dictadura de Primo de Rivera se enajenó la voluntad de los partidos dinásticos hasta tal punto que los proyectos reformistas se hallaban sólo en los programas de los partidos republicanos y de los partidos de clase, y que se dio el caso de que conocidos políticos monárquicos (liberales y conservadores) hicieron pública su adscripción al republicanismo. El delenda est Monarchia de Ortega y Gasset es un excelente reflejo del ambiente y de la crisis política que se daba a comienzos de 1931. Los proyectos reformistas, por lo tanto, se hallaban en los programas de los partidos antidinásticos y el objetivo prioritario de éstos era el derrocamiento de la Monarquía y la proclamación de la República, entendiendo que ésta era el vehículo adecuado para el establecimiento de las reformas.

Los partidos republicanos y los nacionalistas catalanes establecieron una cierta coordinación entre ellos en el mes de agosto de 1930 (el día 17) -Pacto

4. «Una constitución nacional» (art. edit.), Ahora, 11 de septiembre de 1931, p. 3.

5. «La constitución, fórmula de convivencia» (art. edit.), El Debate, 6 de octubre de 1931, p. 1. 
de San Sebastián- en orden a la proclamación de la República mediante la intervención del ejército y la movilización ciudadana; pero esta estrategia quedó anulada a raíz del fracaso de la rebelión de Jaca del mes de diciembre de aquel mismo año, aunque se mantuvo el llamado Comité Revolucionario que se hizo cargo del poder el 14 de abril de 1931, una vez proclamada la República.

Así pues, el proyecto de la democracia republicana era propio de los partidos republicanos y de los partidos de clase y éstos antepusieron la proclamación de la República al establecimiento de un régimen democrático; con lo que el consenso que existía antes del cambio [la transición] se extendía sólo a aquellos partidos. Aquí reside con toda probabilidad el principal problema político que se le planteó al nuevo régimen. Pero antes de continuar conviene hacer algunas consideraciones de carácter semántico. Se entiende por régimen político "el sistema político [conjunto de normas y procedimientos] por el que es regido un Estado»; en cambio, república o monarquía, en sus acepciones más precisas, significan sólo formas de gobierno en las que la Jefatura del Estado recae en un presidente elegido por los ciudadanos o en un rey respectivamente. En consecuencia, en 1931, en España se anteponía el cambio de la forma de gobierno al cambio de régimen, aunque también es cierto que existía un convencimiento generalizado de que el establecimiento de la República en lugar de la Monarquía llevaría consigo la implantación de las reformas políticas y sociales que la segunda había sido incapaz de introducir.

Pero para entender plenamente el problema político que acució al Gobierno republicano es preciso conocer el significado que una gran parte de la sociedad española otorgaba a la República. Aparte del recuerdo histórico de carácter negativo que se guardaba de la I República, no superado aún en la actualidad, la República significaba reformas políticas y sociales radicales, anticlericalismo, enseñanza estatal, laica, pleno reconocimiento y ejercicio de los derechos sindicales, la igualdad efectiva de todos ante la ley, lo que suponía la desaparición de jurisdicciones especiales y privilegios colectivos, y la concesión de las reivindicaciones autonómicas de las regiones históricas. Pero este conjunto de ideas y proyecciones alarmaba a una parte importante de la sociedad española, porque iban en contra de sus intereses económicos y de su status social o porque era sumamente manipulable, dado el bajo nivel cultural de la sociedad española [en torno a un $40 \%$ de analfabetismo en los años treinta], por la intensa influencia que ejercía el clero y la desmovilización social que existía, principalmente en el mundo rural, alentada por la práctica de la política caciquil y las relaciones de deferencia que se habían dado en las décadas anteriores entre la población y los políticos de los partidos dinásticos. Esta situación explicaría el alto porcentaje de votos que obtuvieron las candidaturas monárquicas en las elecciones municipales del 12 de abril de 1931 en los medios rurales; los intentos repetidos por los partidos de la conjunción republicana-socialista para atraer a los partidos de la derecha a las posiciones mayoritarias que defendían el proyecto constitucional y el esfuerzo de la prensa republicana moderada por integrar a la derecha [CEDA] en la política republicana después de su triunfo electoral de noviembre de 1933. 
Así pues, puede hablarse de la existencia de un consenso previo, pero reducido, antes de la implantación de la República, formalizado en el Pacto de San Sebastián, pero que la derecha no reconoció, como puede constatarse en el artículo editorial de El Debate, del 22 de agosto de 1931, en el que se hace referencia explícita a algunas cuestiones que se han mencionado más arriba. En primer lugar, con el propio título del artículo, el convenio privado de San Sebastián, se rechaza la idea de que el pacto consistiese en la búsqueda de una fórmula de consenso, o de transigencia, con la que conseguir el cambio de régimen en España. Para ello utilizan el término "pacto» con los significados estrictos de «acuerdo» o "convenio» $y$ «alianza» [entre países]; por lo que el editorialista argumenta de la siguiente forma:

«El Pacto de San Sebastián no existe. Es decir, no existe para España, que es lo que a todos nos importa. Aquel día 17 de agosto de 1930, en que dicen que el convenio se firmó, España no estaba presente. Ni siquiera lo estaba la revolución que triunfó el 12 de abril en las urnas, ni aún el Gobierno que actualmente nos rige. Estaban allí unos caballeros particulares, sin más representación que la propia, o, a lo más, la de sus amigos políticos, y sin otro título que el de conspiradores.

La revolución no se hizo enarbolando la bandera del Pacto de San Sebastián. En tal caso, todavía pudiera decirse que aquel convenio privado lo había suscrito la gente con sus votos. Pero ni el 12 de abril, ni en elecciones posteriores, se ha hablado a España del Pacto de San Sebastián. En consecuencia, España no tiene por qué reconocerlo y es desagradable que todos los días se nos recuerde aquel Pacto como un compromiso nacional. La representación de España, si no genuina, válida, al menos, jurídicamente, está ahora en el Congreso de los Diputados. Y los actuales miembros de la Asamblea no fueron elegidos porque alzasen como bandera el Pacto de San Sebastián. Muy al contrario, la única bandera que se ha levantado al viento en las elecciones del 28 de junio ha sido la de la soberanía nacional absoluta, la de la guerra a los oligarcas y a las camarillas, en las que unas cuantas personas disponen a su antojo de los destinos del país. Si hubiera compromisos particulares, éstos no serían del Gobierno; menos aún de la Asamblea Constituyente, y menos de toda España».

Con estos argumentos no se rechaza sólo la existencia de un consenso o acuerdo previo para llevar a cabo el cambio de régimen político en España al comienzo de los años treinta sino también el mismo proceso de cambio que el editorialista califica como revolución, situándolo a continuación en lo que pudiera llamarse "punto cero»: la soberanía nacional absoluta, representada jurídicamente en la Asamblea Nacional, aunque después anticipa algunas de sus ideas sobre la cuestión regional:

«... El ambiente hoy en Madrid, en el Congreso, en la prensa, en la calle, es que se va a una Constitución de tipo unitario. Una Patria, un Estado, un Gobierno. Plena soberanía del Estado español en los últimos rincones del territorio nacional. Y esa soberanía, representada por los órganos centrales del Poder, el Gobierno, el Parlamento, el Tribunal Supremo de Justicia».

Y salvado este axioma, a juicio del editorialista, existía una amplia mayoría dispuesta "a conceder a las regiones la libertad precisa para que puedan desen- 
volver su personalidad, a la descentralización [administrativa] de funciones no propias de la soberanía...».

El Pacto de San Sebastián y la trayectoria política de la II República son ejemplos de lo que puede suceder cuando no se cuenta con el consenso suficiente para llevar a cabo un cambio de régimen y su posterior consolidación. Sin embargo, el consenso republicano de 1930-1931 no debe analizarse sólo desde la perspectiva de 1976-1978 sino que hay que situarlo en su propio contexto político: el agotamiento de un régimen liberal, incapaz de evolucionar hacia formas democráticas, y que se apoyó en los últimos años en un gobierno de dictadura. De ahí que la reforma política [implantación de un régimen democrático] llegara con un cambio de régimen y con todas las resistencias de los partidarios del régimen anterior, y en una sociedad muy manipulable, con un nivel de renta muy bajo y una tasa muy alta de analfabetismo.

Por ello no es correcto argumentar en sentido analógico estricto, como lo hace el discípulo de Ortega y Gasset, Julián Marías, en el artículo citado más arriba, cuando, para advertir de los peligros que acechaban al recién formado primer Gobierno de Adolfo Suárez, acudía a la experiencia de la política republicana:

«El Gobierno de la República, desde el comienzo, se dedicó a complacer, contentar, apaciguar o frenar a los grupos que lanzaban sus deseos o caprichos, sus intereses particulares, sus manías u obsesiones históricas. Durante algún tiempo pareció que lo más urgente era derribar la tapia que separaba los cementerios eclesiásticos de los cementerios civiles: por lo visto, los muertos no podían resistir ni una semana más, aquel muro de ladrillo, aunque ello contribuyese a levantar otros más altos entre los vivos. Que desaparecieran los crucifijos de escuelas y hospitales, y las monjas de estos últimos, era también urgente; aunque a los pocos meses tuviera que llamarse a las Hermanas de la Caridad por falta de enfermeras competentes. Mientras se hacía una política positiva, afirmativa, creadora en el campo de la educación... se intentaba una reforma agraria demagógica, perturbada desde el primer momento por el increíble egoísmo de las derechas y por la absurda ley de términos municipales. Se introdujeron temas divisivos, capaces de provocar la discordia, en lugar de unir al país en una empresa capaz de arrastrarlo en una oleada de entusiasmo: expulsión de los Jesuitas, con un burdo pretexto legal; amenazas verbales a la unidad nacional, sin promover el verdadero desarrollo y prosperidad de las regiones; reforma del ejército, para asegurar su adhesión, con los resultados tan brillantemente demostrados cinco años después. Y cuando las derechas triunfaron en las elecciones de 1933, después de un programa hipercatólico destinado a salvar las instituciones amenazadas, perdieron súbitamente su interés por tan elevados fines, y prefirieron reducir bruscamente, hasta los límites de la miseria, los salarios de los obreros y campesinos, ligeramente humanizados en el bienio anterior...».

Con todo, el Pacto de San Sebastián ha sido un referente de la política republicana, de los acuerdos previos a la implantación de un régimen democrático e, incluso, como un modelo para el reparto del poder entre los socios de una coalición gubernamental, tal como lo hace José Luis López Aranguren en un artículo publicado en agosto de 1978: 
"No sé si se ha caído en la cuenta de que el actual régimen de consenso está cumpliendo, después de implantada la predemocracia... una función semejante a la que el régimen de pacto (de San Sebastián) cumplió antes de implantada la República de 1931; que esa función consiste y consistió en definir cuáles son los partidos con derecho a gobernar, aquellos a quienes se otorgan credenciales, republicanas entonces, democráticas ahora, el partido republicano conservador de los ex monárquicos Alcalá Zamora y Miguel Maura y la UCD de los ex franquistas, respectivamente; y en definir asimismo, quienes son aquellos que, por la izquierda $y$, sobre todo, por la derecha, quedan excluidos, entonces la CEDA, ahora Alianza Popular. Naturalmente, la constelación de fuerzas puede cambiar por virtud del sufragio y, llegado ese caso, del mismo modo que algunos de esos que fueron admitidos, así Alcalá Zamora, y otros que entrando por derecho histórico en el pacto, más o menos venalmente lo traicionaron, así Lerroux, pudieron hacer girar a la República a la derecha, hasta desnaturalizarla, el día de mañana algunos miembros de UCD podrían hacer girar la, llamémosla así, democracia actual, hacia el más cerrado conservadurismo...» ${ }^{6}$.

Las circunstancias en las que se configura el consenso de 1976-1978 eran radicalmente distintas: con la muerte del general Franco se diluía un régimen político, anacrónico desde hacía tres décadas, e inviable, incluso, para la mayoría de los que habían sido sus partidarios. Desde los últimos años de la década de los cincuenta la economía y la sociedad españolas se habían modernizado $y$, en buena medida, se hallaban homologadas con las de los países democráticos del entorno europeo y occidental. Pero esta sociedad moderna chocaba permanentemente con las limitaciones y el intervencionismo político y cultural del régimen de dictadura; por lo que desde la percepción generalizada de la incompatibilidad existente entre el desarrollo económico y social de la población española y el régimen franquista surge el convencimiento de que se han de adoptar formas de gobierno democrático, como único procedimiento para alcanzar la homologación completa con los países democráticos europeos. Ésta es la base real sobre la que se apoyará el amplio consenso para el establecimiento de la democracia en España.

La prensa, y particularmente los periódicos que nacieron en los inicios de la Transición -Diario 16 y El País-, ya citados repetidamente, actuaron como el registro más fiel. En Diario 16, al día siguiente de aprobarse en las Cortes la Ley para la Reforma Política, podía leerse:

«... Detrás de la operación de desmantelamiento del franquismo está el país entero, con una unanimidad que espanta. Hasta las Cortes de la dedocracia, hasta esos procuradores que nunca eligió nadie, hasta esos líderes sindicales de color azul que hablan del mundo obrero como si fuera propio, pero al que nunca quisieron consultar, hasta todo ese variopinto mundo de las Cortes franquistas había llegado ensordecedoramente la opresión de la opinión nacional. El pueblo español exige su derecho a nombrar, revocar y controlar a su propio Gobierno.... ${ }^{7}$.

6. López Aranguren, José Luis, «El consenso de la Moncloa y el «pacto» de San Sebastián», El País, 19 de agosto de 1978.

7. «Enhorabuena, español» (art. ed.), Diario 16, 19 de noviembre de 1976, p. 4. 
Pero para llegar al consenso, para concretarlo, era preciso recorrer un camino ya que las propuestas de la oposición democrática no coincidían con las del Gobierno de Suárez, al menos en el procedimiento a seguir -ruptura frente a reforma-. Por ello, Diario 16 expresaba su satisfacción porque la oposición democrática, con el espectro más amplio posible - «desde sectores del centroderecha a la extrema izquierda»-, había establecido una plataforma básica de negociación, que comentaba de la siguiente forma:

«La oposición, en un alarde de madurez y buen sentido que debe ser calurosamente aplaudido, ha fijado un programa mínimo y razonable evitando plantear temas políticos, sin subirse a la parra ni pedir la Luna. La transición hacia la democracia está siendo aquí excesivamente peculiar por haberse iniciado partiendo de las instituciones de la dictadura; pero si el objetivo democrático es sincero y no una simple cortina de humo para camuflar el continuismo, las premisas fijadas por la «cumbre» de la oposición son indispensables e irrenunciables. El reconocimiento de todos los partidos y sindicatos, la garantía de las libertades públicas, la igualdad de acceso a los medios oficiales de comunicación, la neutralidad de la Administración con la consiguiente disolución del Movimiento, no pueden ser vistos por el Gobierno como exigencias de nadie ni como imposiciones extemporáneas.... ${ }^{8}$.

Al día siguiente de la celebración del referéndum "para la reforma política», el 16 de diciembre de 1976, el editorialista de Diario 16 enunciaba los objetivos prioritarios que debía cumplir la política española [el Gobierno de Adolfo Suárez] "para la construcción de la democracia en este país», lo que suponía, al mismo tiempo, el consenso básico existente, tal como se afirma en el punto segundo. Los objetivos eran los siguientes:

1) «Establecimiento y garantía de las libertades públicas... El Gobierno puede arrinconar sin más todas las normas represivas y restrictivas del franquismo por incompatibles con el nuevo régimen aprobado por voto popular».

2) "Iniciar las negociaciones con la oposición democrática... Todos los puntos que aquí se señalan deben ser objeto de diálogo con los partidos a los que debe asociarse a la operación de la transición como participantes a parte entera y de pleno derecho".

3) «Promulgar una ley electoral negociada que deje reducida al mínimo las posibilidades de desigualdades de representación...».

4) «Fijar las bases de un compromiso constitucional para evitar que la discusión sobre la futura constitución se prolongue innecesariamente o sea ocasión de enfrentamientos insolubles. Esto supondría tanto el acuerdo sobre un esquema mínimo constitucional como el establecimiento de un plazo para redacción de la constitución...».

5) «Establecimiento de un plan económico de urgencia con participación de todos los partidos y sindicatos libres para remediar la grave situación económica...».

8. «Las siete condiciones de la oposición» (art. ed.), Ibidem, 29 de noviembre de 1976. 
6) «Llevar a cabo las reformas administrativas necesarias para desmantelar el aparato de la dictadura y adaptar la Administración a la nueva situación democrática...».

7) «Abordar la cuestión de las autonomías regionales, estableciendo ya las condiciones para el debate que ha de culminar en la normativa constitucional sobre el tema».

8) «Establecimiento de la unidad de jurisdicciones con la consiguiente supresión de los tribunales especiales, como el TOP, y limitación de la jurisdicción militar a un ámbito natural»?

Otra etapa importante del proceso de confirmación del consenso es la que se desarrolla en torno a la firma del Pacto de la Moncloa, en octubre de 1977, cuatro meses después de celebrarse las primeras elecciones generales, y que el editorialista de Diario 16 calificaba como "un pacto para la democracia». En el artículo, analizando el comportamiento de los principales partidos políticos -UCD, PSOE y PC- se relacionan estrechamente dos ideas, a las que ya se ha aludido más arriba: cambio político y bienestar económico, y partiendo de esta relación el editorialista concluía de la manera siguiente:

«El final de la historia es un país moderado que desea un cierto cambio pero dentro de un bienestar económico. Ese espacio político es el centro o centro-izquierda y todos los partidos intentan situarse en dicho espacio, olvidándose de sus textos sagrados y catecismos.

Este espacio político donde se enmarca la gran mayoría del país pedía salir adelante en la crisis y consolidar la democracia, y esto suponía una negociación política o un acuerdo tácito.

El problema que queda es que este país puede estar dispuesto a sacrificarse siempre que los sacrificios se repartan, y aquí entran en juego las contrapartidas anunciadas en el plan que deben mostrar al país el deseo de cambio y reforma profunda ${ }^{10}$.

Enlazando con el último párrafo citado, el artículo editorial del día siguiente, 12 de octubre, se titula "ensanchar el pacto" y trata de la necesidad de que los empresarios y las centrales sindicales se adhieran al pacto porque eso es lo que conviene a la sociedad española. Con esta perspectiva las expresiones y admoniciones del editorialista resultan contundentes:

«El compromiso de los políticos ha de bajar a las calles y a las fábricas, y en ellas encontrar su engarce con la realidad del país. Es imprescindible. Si algún empresario incurre en el espejismo de no sentirse representado por sus políticos, que afine su juicio, porque está representado, y bien. Y si alguna central sindical se siente tentada de aprovechar la inevitable impopularidad del compromiso para enganchar nueva clientela, que busque mejor ocasión para el proselitismo y tenga el coraje de afrontar la impopularidad, si es que llega, antes de hacer méritos para abortar un proceso constituyente, que es, por ahora, la única garantía de su supervivencia».

9. "Y ahora, วंqué?» (art. ed.), Diario 16, 16 de diciembre de 1976, p. 4.

10. «Un pacto para la democracia» (art. ed.), Diario 16, 11 de octubre de 1977, p. 4. 
Una prueba más del funcionamiento del consenso procede de la identificación de aquellos que lo denigran, dirigentes de partidos o grupos políticos minoritarios, que no habían obtenido representación parlamentaria en las elecciones de junio de 1977. Tal es el caso de José María Gil Robles, quien, aparte de calificar al consenso de "famoso y confuso", se atreve a advertir a los partidos mayoritarios de alejarse de la opinión pública y de sus representados por mor de esta práctica parlamentaria, como ya sucediera, a juicio del articulista, a la conjunción republicano-socialista, en el bienio de 1931 a $1933^{11}$. El mismo autor, un mes más tarde, arremetía de nuevo contra el consenso que se practicaba en la Comisión Constitucional del Congreso de los Diputados, a propósito del debate sobre el artículo segundo -unidad de la Patria y autonomía de nacionalidades y regiones-, en donde, aparte de destilar viejas ideas de tipo corporativo, llegaba a afirmar:

"La droga del "consenso", tan propicio a las concesiones mutuas para acallar de momento las discrepancias, ha llevado a nuestros constituyentes a incrustar en la ley fundamental un principio potencialmente disolvente, que ennegrece no poco las perspectivas de futuro ${ }^{12}$.

De forma semejante argumenta también Carlos Hugo de Borbón Parma, presidente del Partido Carlista, quien, después de afirmar que la función de los grupos de la oposición parlamentaria es ejercer la crítica en nombre del pueblo y públicamente, califica al consenso de "sospechoso" $\mathrm{y}$ "ambiguo», llegando a afirmar:

«La actual oposición parlamentaria no sólo da la sensación de traicionar la función crítica, es decir, el proceso democrático, sino, incluso, la misma lucha democrática de amplios sectores del pueblo y del mismo gobierno ${ }^{13}$.

A pesar de las evidentes virtudes, e incluso de la necesidad, de la política de consenso en los procesos de transición democrática, ha de tenerse en cuenta, como ya se ha indicado más arriba a propósito del análisis de Raúl Morodo, que este tipo de política, por su propia naturaleza, es provisional y sólo destinada al establecimiento de los acuerdos previos para llevar a cabo el proceso de transición a la democracia y a la creación del marco legal -constitucional- dentro del cual se practique la normalidad democrática. Esta tesis era defendida por Felipe González, a punto de aprobarse la Constitución, cuando recordaba al Gobierno de Suárez que o convocaba elecciones generales o se sometía a un voto de investidura para conseguir la mayoría necesaria. Es decir, con la aprobación de la Constitución la política de consenso terminaba y, por tanto, la de la provisionalidad.

11. GIl Robles, José María, «Parlamento y democracia», El País, 15 de abril de 1978.

12. GIL Robles, José María, «¿Consenso o narcótico?», El País, 25 de mayo de 1978.

13. De Borbón PARMA, Carlos Hugo, "El Parlamento y la política de consenso», El País, 29 de abril de 1978. 


\section{LAS DIFICULTADES INTERNAS DEL CONSENSO}

Como ya se ha dicho más arriba, el que el consenso consista en un acuerdo previo para llevar a cabo un proceso de transición a la democracia, esto no implica que a lo largo de dicho proceso puedan surgir desacuerdos entre los grupos comprometidos que empuje a algunos a romper el consenso o a la búsqueda de nuevos pactos a colocar en el marco general del consenso.

No pretendo aquí hacer un recorrido por los debates constitucionales de 1931 y 1978 para marcar los puntos de desacuerdo y las soluciones que se buscaron para superarlos sino sólo subrayar las cuestiones fundamentales que dieron lugar a los disensos entre los grupos que habían asumido el consenso previo. No por casualidad existe un gran paralelismo entre los enunciados referentes a 1931 y 1978 ya que la vida convulsa de la II República y su posterior derrocamiento dejaron pendiente durante la larga dictadura franquista el tratamiento en profundidad de aquellas cuestiones.

En el ya citado periódico republicano Ahora, con motivo del debate de la totalidad del proyecto constitucional en las Cortes, se decía:

«Por de pronto ya se va viendo claro que la verdadera discusión girará en torno a tres cuestiones fundamentales: estructura del Estado (problema de las relaciones entre el Estado central y los organismos más o menos autónomos que se creen), problema religioso (relaciones entre la Iglesia y el Estado y situación de las Órdenes religiosas) y problema de la propiedad. Y aún este último pudiera descartarse, porque, en último término, se reduce a una pura declaración doctrinal, con lo que su discusión se simplificará mucho. Aún cabría añadir el de los poderes del Presidente de la República y su forma de elección, y el del divorcio; pero tampoco éstos tienen la complejidad de los dos primeros, que serán, sin duda, los campos de verdadera lucha $»^{14}$.

Igualmente, a comienzos de mayo de 1978, con motivo de empezar los debates del anteproyecto de la Constitución en la Comisión del Congreso de los Diputados puede leerse en un artículo editorial del diario El País:

«Las grandes cuestiones sobre las que no existe unanimidad o falta un elevado grado de consenso, son ya conocidas: la forma política del Estado; la dialéctica entre unidad de la nación española y el derecho a la autonomía de las comunidades históricas y de las regiones; la compatibilidad entre la aconfesionalidad del Estado y la expresa mención a la Iglesia católica entre las confesiones con las que los poderes públicos mantendrán relaciones de cooperación; la conciliación entre el objetivo de una educación obligatoria y gratuita, los derechos de los ciudadanos a elegir la formación religiosa y moral de sus hijos, las subvenciones de fondos públicos a centros docentes privados y el control de la forma en que aquéllas se asignen y administren; la definición de las fronteras del sistema económico, los deberes y los derechos de los empresarios y de los asalariados y los ámbitos de acción de la iniciativa privada y del sector público; la forma de designar y deponer al presidente del gobierno y las relaciones entre los poderes legislativo y ejecutivo; los procedimientos para garan-

14. «Una constitución nacional» (art. ed.), Ahora, 11 de septiembre de 1931, p. 3. 
tizar la independencia del poder judicial y los derechos de los jueces y magistrados como ciudadanos y como miembros de ese tercer poder. Etcétera» ${ }^{15}$.

En 1931, los problemas más arduos, sin ningún género de duda, fueron el de las autonomías de las regiones y el religioso, que enfrentó a los grupos parlamentarios de la derecha con la conjunción republicana-socialista y produjo la deserción de los republicanos liberal-demócratas de la coalición gubernamental (Alcalá Zamora y Miguel Maura, presidente provisional del Ejecutivo y ministro de la Gobernación, respectivamente).

Aparte de la reflexión anterior del periódico Ahora, el diario El Debate ofrece una muestra evidente de la evolución de los debates parlamentarios que no sirvieron en absoluto para ampliar el consenso sino para profundizar en el enfrentamiento entre los grupos parlamentarios de la derecha con la coalición gubernamental e, incluso, para abrir graves fisuras dentro de ésta.

Ya se ha hecho referencia más arriba a la cuestión de las autonomías regionales pero el problema central para el grupo que se sentía representado por $E l$ Debate fue el religioso. De forma premonitoria escribía el editorialista, el 9 de septiembre de 1931:

«Necesita el régimen de esta colaboración (de los católicos), primero, para implantar la constitución misma. Menos que de talla mediocre sería el gobernante que no viera la gravedad de que el día que se implantara la constitución un sector del país creyese que no es la suya, la gravedad de que al día siguiente de publicarse la constitución los católicos tuvieran que decir: es indispensable que esa constitución se modifique, porque así lo exigen los derechos de la Iglesia. Guerra civil sería ésta, no de esa guerra civil absurda e inverosímil de que se ha hablado, sino guerra civil incruenta que dividiría a los ciudadanos españoles en dos castas: unos, dentro de la constitución, y otros, prácticamente excluidos por la constitución de la vida pública. Como ha dicho con acierto el Sr. Maura, eso equivaldría a que, al publicarse el texto constitucional, no quedase cerrado el periodo constituyente. Al tiempo que la ley fundamental apareciese en la "Gaceta", una masa enorme de españoles pediría su revisión. Ese sería el mayor fracaso de un gobierno y de una asamblea, cuya misión es la de hacer una constitución para España. Por el contrario, si la constitución representa una transacción noble y leal, ¡de cuán distinta manera sería recibida! » ${ }^{16}$.

Un mes más tarde, a punto de comenzar los debates sobre la cuestión religiosa, el mismo diario volvía sobre el tema refiriéndose sin ambages a la situación política y al concurso que podían hacer las organizaciones de la derecha de la siguiente manera:

"Comienza hoy una semana parlamentaria en verdad crítica para la Iglesia en España; mas también para la República, aún muy lejos de su consolidación. La Republica española atraviesa un periodo de crisis mucho más aguda de lo que corresponde a un régimen político naciente (...) Para la obra definitiva de consolidación del régimen, el concurso político de las derechas españolas y el moral de la Iglesia puede ser definitivo; desde luego, interesantísimo... Al mismo tiempo que por la izquierda álzanse

15. "Comienza el gran debate» (art. ed.), El País, 5 de mayo de 1978.

16. «El necesario ambiente de paz» (art. ed.), El Debate, 9 de septiembre de 1931. 
contra la República, al menos contra «esta» República, los enemigos más encarnizados, que son precisamente sus aliados de ayer. El concurso de las derechas españolas está asegurado sólo con esto: que no se lleve a la Constitución ningún artículo que impida a la Iglesia la celebración de un Concordato, que las relaciones entre la Iglesia y el Estado se pacten con el mismo leal espíritu inspirador de tantos Concordatos concertados por la Santa Sede con Repúblicas civilizadas y modernas» ${ }^{17}$.

Respecto al problema agrario, el comentario del diario Ahora fue certero en cuanto a la actitud manifestada por El Debate. Después de una declaración de principios, el 27 de agosto de 1931, siguiendo el pensamiento social y político de la Iglesia, en donde llega a decir:

«Es necesario ir a reformas entre las cuales se halla en destacadísimo término la que ahora se dispone a emprender el gobierno español. Y esto no se puede conseguir más que como el gobierno se lo propone: tomar tierras, expropiándolas debidamente, entregárselas a los trabajadores y darles medios para que las cultiven» ${ }^{18}$.

A medida que fue aumentando la influencia del grupo de «los agrarios» en la derecha y sobre los católicos, las posiciones defendidas por El Debate, a la par que se concretaban, se endurecían ${ }^{19}$. No debe olvidarse que en la rebelión del general Sanjurjo, de agosto de 1932, subyacían entre otros problemas el Estatuto de Autonomía de Cataluña y la Ley de Reforma Agraria.

Así pues, ni los debates constitucionales ni la trayectoria política de la República durante el bienio azañista sirvieron para que los grupos de la derecha se integraran en el consenso, más al contrario, crecieron los desacuerdos y surgieron enfrentamientos entre los grupos que formaron la primera conjunción republicano-socialista que no siempre se superaron, como fue el caso de los republicanos radicales.

Las circunstancias en las que se realizó el consenso de 1976-1978 fueron distintas, como ya se ha dicho más arriba. Existió, en primer lugar, un acuerdo previo que, aunque necesitó actualizarse sucesivamente, a medida que fue concretándose, planeó sobre todo el proceso de transición a la democracia, como se puso de manifiesto repetidas veces a lo largo de los debates entre los representantes de los distintos grupos parlamentarios en la ponencia constitucional y en la Comisión correspondiente del Congreso de los Diputados. Al día siguiente de comenzar el debate en Comisión, Diario 16 juzgaba el proceso de la siguiente manera:

«... El pueblo español ha dado al mundo entero una insuperable lección de cultura, inteligencia y autodominio. El camino que aún queda por recorrer es largo, pero su horizonte se nos aparece cada vez más cercano. El ancestral temor va quedándose rezagado.

Estamos en el comienzo de un debate en el que el ochenta por ciento de la materia a discutir ya está prácticamente aceptada por la totalidad de las fuerzas políticas

17. «La constitución, fórmula de convivencia» (art. ed.), El Debate, 6 de octubre de 1931.

18. "Ante la reforma agraria» (art. ed.), El Debate, 27 de agosto de 1931.

19. "Ante el dictamen sobre reforma agraria» (art. ed.), Ibidem., 9 de octubre de 1931. 
en liza. El pacto constitucional está, por tanto, en su mayor parte consumado. Y, en consecuencia, vamos a gozar de una constitución lograda por consenso y aceptada por todas las organizaciones democráticas mayoritarias.

Quedan, es cierto, algunos puntos que todavía se presumen no enteramente debatidos en los filtros de la ponencia constitucional. Sobre ellos se materializará el verdadero debate que ayer se abrió. Tales son el tema de la enseñanza, el de la Iglesia Católica, el del modelo económico, las autonomías o nacionalidades, el formalmente vidrioso problema de la Monarquía y la República y el papel del Senado» ${ }^{20}$.

En la semana del 22 al 26 de mayo se daría un avance muy considerable en el debate constitucional. Los dirigentes de los principales grupos parlamentarios eran conscientes de la lentitud del proceso y, por lo tanto, de la conveniencia de acelerarlo. Diario 16, en su artículo editorial del 24 de mayo lo planteaba de esta forma:

«Es insostenible mantener por más tiempo el ya largo periodo de transición de la dictadura a la democracia constitucionalizada. Los políticos empiezan a considerar seriamente el posible cansancio del pueblo en general y de sus respectivos votantes en particular, desorientados por ofertas electorales poco diferenciadas».

Por ello, el lunes, veintidós de mayo, se celebró una reunión entre los principales dirigentes de la UCD y del PSOE que propiciaron aquel avance. Diario 16, en el citado artículo editorial, se expresaba así:

«... En las últimas cuarenta y ocho horas gobierno y oposición han decidido dar un fuerte acelerón a la elaboración del anteproyecto constitucional. Y la única manera de imprimir velocidad, han coincidido, es a través del pacto entre los máximos dirigentes de los partidos que protagonizan la vida política del país.

Dos consecuencias se han derivado de esta manera de proceder: la marginación de las minorías parlamentarias menos cualificadas y el paso a un segundo plano de la Comisión constitucional...

Ayer se avanzó considerablemente en la elaboración de la constitución tras el pacto previo, entre bastidores, entre los dos partidos mayoritarios, UCD y PSOE. Comunistas y nacionalistas catalanes tuvieron acceso a las negociaciones, y Alianza Popular asistió tardíamente como testigo. Si Fraga, ausente en el extranjero, ha estado al margen, también sería problemático.

Los socialistas consiguieron que UCD cediera ante algunas de sus importantes aspiraciones. El centro cedió por imposición directa de la Moncloa. De esta manera se recompuso el consenso alcanzado en la ponencia constitucional a primeros de año, UCD consiguió de los socialistas el firme respeto a la economía de mercado con tímidos correctores al sistema capitalista. Así, el resultado final será una constitución liberal-progresista» ${ }^{21}$.

20. «Recta final de la constitución» (art. ed.), Diario 16, 6 de mayo de 1978, p. 4. A continuación el editorialista analiza detenidamente cada uno de estos puntos pero no considero necesario reproducirlo porque ello no afecta a nuestro hilo argumental.

21. "Pacto constitucional» (art. ed.), Diario 16, 24 de mayo de 1978, p. 4. Al día siguiente, 25 de mayo, el diario El País se refería a la misma cuestión en su artículo editorial titulado "Alianza Popular cabalga de nuevo", en el que analiza las razones de la marginación de AP y del PNV. 
Estas posiciones políticas se mantuvieron hasta el final de los debates en la Comisión constitucional; de ahí que cuando el proyecto llegó al Pleno del Congreso de los Diputados, el editorialista de Diario 16 escribiera:

«El debate se presenta como un mero trámite para los partidos mayoritarios, a excepción de Alianza Popular y el Partido Nacionalista Vasco. UCD, PSOE, PCE y nacionalistas catalanes dan ya por bueno el texto, mientras que el partido conservador de Manuel Fraga y los nacionalistas, cada uno desde perspectivas distintas, quisieran introducir importantes modificaciones.

El partido del Gobierno está plenamente satisfecho con el proyecto de Constitución. Socialistas, comunistas y nacionalistas catalanes, sin romper el pacto, plantearán sólo algunos cambios...

La mayor preocupación que se suscita al comienzo del debate en el Pleno del Congreso gira en torno a si las posturas de AP y el PNV serán meramente testimoniales o si realmente lucharán por modificar sustancialmente el pacto ya sellado. En otras palabras, existe la incógnita sobre si estos dos partidos consideran totalmente inaceptables algunos aspectos del proyecto constitucional o si defenderán lo que moralmente se ven obligados a defender de cara a su electorado ${ }^{22}$.

El PNV no se avino a la integración en el pacto y AP, como consecuencia del debate constitucional, se fragmentó, produciéndose el alejamiento de Gonzalo Fernández de la Mora y Federico Silva Muñoz que, según Diario 16, "han vuelto a su redil franquista, del que nunca debieron salir ${ }^{23}$.

\section{CONCLUSIÓN}

Después de este largo recorrido por los procesos consensuales de las constituciones de 1931 y 1978, se ha de volver al principio para clarificar la función del consenso en la implantación de los regímenes democráticos. Para ello se han de tener en cuenta varios elementos.

Primero, la naturaleza de las democracias como regímenes de las libertades, y especialmente de las de información y opinión. Un régimen democrático precisa de la integración de todos los ciudadanos, de forma individual o través de los partidos políticos y de las organizaciones sociales. Por lo tanto, su implantación necesita el acuerdo mayoritario de los ciudadanos, que deben conocer las propuestas de los partidos, lo que se les ofrece y lo que se les va a pedir, pero, sobre todo, han de valorar la obtención y el disfrute de las libertades y el ser dueños de su propio destino.

22. «Pleno constituyente» (art. ed.), Diario 16, 4 de julio de 1978, p. 4. El mismo día, el diario El País se expresaba en términos parecidos en su artículo editorial, «El Pleno de la Constitución», recomendando la reintegración de $\mathrm{AP}$ al consenso constitucional pero percibe mayores dificultades en la actitud del PNV por la reivindicación de los fueros y la indecisión ante las actuaciones de ETA.

23. «AP, sector renovado» (art. ed.), Diario 16, 16 de noviembre de 1978, p. 4. El País hacía referencia a la misma cuestión en su artículo editorial del 3 de noviembre, "Alianza Popular: los restos del naufragio», que concluía de la siguiente manera: «Su negativa (de Fernández de la Mora y Silva Muñoz) a la Constitución es, en definitiva, una buena noticia, porque consuma el final práctico de un franquismo vergonzante que no tiene sitio en la España democrática». 
Segundo, las circunstancias en las que se produce la implantación del régimen democrático. Un componente fundamental de las sociedades es su temporalidad, su historicidad, y esto constituye el objeto principal del trabajo del historiador. La implantación de la II República y del actual régimen democrático, como ya he indicado más arriba, tienen un antecedente inmediato similar, regímenes de dictadura, más radical y prolongada la franquista que la de Primo de Rivera, pero que generan tendencias semejantes a la ampliación de los derechos fundamentales y de los márgenes para la participación de los ciudadanos en la política y en la vida pública.

Tercero, la situación de la sociedad cuando se lleva a cabo la implantación del régimen democrático. España en 1931 era una sociedad económicamente subdesarrollada, de nivel cultural muy bajo y política e ideológicamente muy manipulable. Parte de la minoría dirigente, la de los partidos antidinásticos, desde la segunda década del siglo, estaba pidiendo la democratización del régimen de la Restauración y de la vida pública, pero aquél no podía concederlo porque supondría ir en contra de su naturaleza. De ahí que pueda considerarse coherente la formación de un gobierno de dictadura con el consentimiento del Rey, en septiembre de 1923; por lo que el futuro de la Monarquía quedaba atado a la dictadura de Primo de Rivera. En consecuencia, cuando cayó éste, Alfonso XIII fue incapaz de restablecer el régimen de la Restauración. Pero las libertades que había negado la Monarquía fueron reivindicadas en nombre de la República; de ahí que en la percepción de la sociedad española la República [forma de gobierno] se presentara como régimen capaz de modernizar al Estado y reformar la vida pública, lo que se mantuvo como prioritario a la implantación de un régimen propiamente democrático.

Pero la República se definía ante la opinión pública por las organizaciones políticas herederas de la Monarquía como un tipo de Gobierno radical, laico, que atentaba contra la unidad de España y el derecho de la propiedad; y ni los enemigos de la República cambiaron su discurso ni el Gobierno republicanosocialista pudo sacudirse aquellos apelativos, a pesar de la importante labor reformista que llevaron a cabo y de la elaboración de una de las constituciones más democráticas de la época. En aquella situación no fue posible la realización de un acuerdo previo generalizado y quedó reducido a los límites del Pacto de San Sebastián, que la propia trayectoria política de la II República reduciría aún más. El final de aquel régimen democrático es conocido por todos: los enemigos del régimen concertados con los sectores más reaccionarios del ejército dieron un golpe de Estado.

Pero la situación de la sociedad española a mediados de los años setenta había cambiado profundamente. El régimen franquista era inviable, una vez desaparecido su fundador, y el establecimiento de un régimen democrático era el único elemento que faltaba para que la sociedad española se homologara plenamente con las de los países de su entorno. Este convencimiento compartido por los herederos reformistas del franquismo, que consideraban a éste como el principal obstáculo que se oponía a la completa modernización del país, y por la oposición democrática, que moderó sus posiciones para evitar recaídas 
de tipo autoritario ${ }^{24}$, favoreció el acuerdo previo y recompuso el consenso a lo largo del proceso de la transición democrática siempre que fue preciso. En este caso el debate sobre las formas de gobierno -Monarquía o República- quedaba sumido en el objetivo prioritario de implantar un régimen democrático. De la generalidad del consenso es una muestra fehaciente la ínfima representación parlamentaria que obtuvieron los continuistas del franquismo en las elecciones generales de 1977.

Así pues, lo que no pudo ser en 1931, se consiguió entre 1976-1978.

24. Sobre la moderación de los partidos de la oposición democrática en el proceso de transición a la democracia influyó de manera importante el cúmulo de experiencias negativas y muy dolorosas sufridas por la sociedad española en la Guerra Civil y la larga dictadura franquista. Ver ARÓsTEGUI, Julio, «La mémoire de la guerre civile et du franquisme dans l'Espagne démocratique», Vingtième Siècle. Revue d'Histoire, n. ${ }^{\circ}$ 74, avril-juin, 2002, Paris, pp. 31-42. 